\title{
АКТУАЛЬНЫЕ ВОПРОСЫ ПОДОХОДНОГО НАЛОГООБЛОЖЕНИЯ В ПУБЛИЧНЫХ ЗАКУПКАХ РОССИЙСКОЙ ФЕДЕРАЦИИ
}

\begin{abstract}
В.В. Кикавец*
Рассмотрены налоговые последствия участия физических лиц в публичных закупках Российской Федерации. На основании анализа норм действующего законодательства, с учетом проекции на ситуации правоприменительной практики, выявлены проблемы, связанные с исчислением и удержанием подоходного налога в публичных закупках. Исследованы вопросы, связанные: с приобретением или утратой физическим лицом - контрагентом по государственному (муниципальному) контракту или гражданско-правовому договору статуса индивидуального предпринимателя, с применением физическим лицом статуса «самозанятого гражданина» (использование специального налогового режима - налог на профессиональный доход), с применением прогрессивной налоговой шкалы (налога на богатых с 2021 г.). Сформулированы предложения в части оптимизации взаимодействия должностных лиц заказчика, направленной на недопущение налоговых правонарушений в сфере закупок.
\end{abstract}

Ключевые слова: публичные закупки, физическое лицо, подоходный налог, самозанятый гражданин, налог на профессиональный доход, заказчик, налоговый агент.

JEL-классификация: К34, H24.

DOI: $10.46782 / 1818-4510-2021-2-118-124$

Материал поступил 6.05.2021 2.

Публичные закупки в Российской Федерации реализуются на основе двух базовых законов: Федерального закона от 18.07.2011 г. № 223-Ф3 «О закупках товаров, работ, услуг отдельными видами юридических лиц» (далее - Закон № 223-ФЗ) и Федерального закона от 05.04.2013 г. № 44-Ф3 «О контрактной системе в сфере закупок товаров, работ, услуг для государственных и муниципальных нужд» (далее - Закон № 44-ФЗ)ํ.

Поскольку Гражданский кодекс Российской Федерации (далее - ГК РФ), а также вышеназванные законы предусматривают возможность участия в публичных закупках физических лищ ${ }^{2}$, порядок исчисления и уплаты подоходного налога в случае заключения и исполнения государственного (муни-

\footnotetext{
${ }^{1}$ URL: http://kremlin.ru/acts/bank/33622; URL: https:/ /fas.gov.ru/documents/611979

${ }^{2}$ Ст. 18, п. 1 ст. 23 ГК РФ; ч. 5 ст. 3 Закона № 223-ФЗ; п. 4 ч. 1 ст. 3 Закона № 44-ФЗ.
}

ципального) контракта либо договора гражданско-правового характера ${ }^{3}$ с физическим лицом представляет значительный интерес. Физические лица могут исполнять договоры, заключенные с ними, как по итогам проведения конкурентных закупок, так и путем закупки у единственного поставщика (подрядчика, исполнителя).

Проблемы налогообложения в публичных закупках рассматривались неоднократно, но преимущественно в части уплаты налога юридическими лицами ${ }^{4}$ (Кикавец, Копина, 2018; Кикавец, 2019a, b). Вопросы подоходного налога в публичных закупках

\footnotetext{
${ }^{3}$ Понятия «государственные (муниципальные) контракты» и договоры гражданско-правового характера» для цели настоящей статьи объединим в общее понятие «договор».

${ }^{4}$ Кикавец В.В. 2019. К вопросу о введении специального налогового режима в контрактной системе в сфере закупок. Налоговая система Российской Федерации в условиях развития цифровой экономики: правовые и экономические асnекты: материалы Международной научно-практической конференции. Москва: РГУП. С. 114-120.
}

* Кикавец Виталий Викторович (viking0071@mail.ru), кандидат юридических наук, доцент, Российский государственный университет правосудия (г. Москва, Россия). 
стали приобретать актуальность за последнее время в связи с предоставлением физическому лицу действующим законодательством Российской Федерации ряда возможностей, таких как:

- непосредственное участие в качестве физического лица;

- участие как зарегистрированного в качестве «самозанятого гражданина», применяющего специальный налоговый режим (налог на профессиональный доход - НПД) в рамках Закона № 422-Ф35;

- участие как зарегистрированного в качестве индивидуального предпринимателя (далее - ИП).

На необходимость акцентирования внимания на проблемах налогообложения физических лиц в публичных закупках указывает и тот факт, что должностные лица заказчика, отвечающие за реализацию публичных закупок, не обязаны в полном объеме контролировать вопросы налогообложения. Вместе с тем, согласно Налоговому кодексу Российской Федерации ${ }^{6}$ (далее НК РФ), заказчик по отношению к физическому лицу - контрагенту по договору является налоговым агентом и несет налоговую ответственность за налоговые правонарушения (п. 1 ст. 226 НК РФ).

Рассмотрим поочередно вышеуказанные возможности участия физических лиц в публичных закупках в сочетании норм действующего законодательства Российской Федерации. Согласно нормам НК РФ, вознаграждение по договору возмездного оказания услуг или подряда облагается налог на доходы физических лиц (НДФЛ) (пп. 6 п. 1 ст. 208 НК РФ).

В действующей редакции ч. 13 ст. 34 Закона № 44-ФЗ прямо предусмотрена обязанность заказчика при заключении контракта с физическим лицом в такой контракт включить условие об уменьшении суммы, подлежащей уплате заказчиком физическому лицу, в том числе зарегистрированному в качестве ИП, на размер налогов, сборов и иных обязательных платежей в бюджеты бюджетной

5 Федеральный закон от 27.11.2018 г. № 422-Ф3 «О проведении эксперимента по установлению специального налогового режима «Налог на профессиональный доход». URL: http://kremlin.ru/acts/bank/43826

${ }^{6}$ Налоговый кодекс Российской Федерации (часть вторая) от 05.08.2000 г. № 117-Ф3. URL: http:// www.kremlin.ru/acts/bank/15925 системы Российской Федерации, связанных с оплатой контракта, если в соответствии с законодательством Российской Федерации о налогах и сборах такие налоги, сборы и иные обязательные платежи подлежат уплате в бюджеты бюджетной системы Российской Федерации заказчиком. В данном случае заказчик обязан уплатить в бюджет за физическое лицо НДФЛ, а также все необходимые страховые взносы, удерживаемые из цены контракта, заключенного по итогам конкурентных процедур. Однако при заключении договора с единственным поставщиком (подрядчиком, исполнителем) заказчик на свой выбор может самостоятельно заплатить сборы и обязательные платежи в бюджет в отношении физического лица, что соотносится с первоначальной редакцией ч. 13. ст. 34 Закона № 44-Ф3, которая не обязывала заказчика уменьшать цену договора на страховые взносы, оставляя последнему дискрецию выбора: все полностью удержать из цены договора либо уменьшить цену договора на размер подоходного налога, а страховые взносы отнести на дополнительные издержки заказчика.

Закон № 223-ФЗ не содержит нормы, прямо обязывающие заказчика удерживать подоходный налог с физических лиц при оплате цены договора, корреспондируя, по сути, к общим нормам действующего законодательства, а также к определенным алгоритмам работы заказчика в рамках Положения о закупках. Вместе с тем в рамках эксперимента по установлению специального налогового режима НПД в отношении физических лиц, не являющихся ИП, в ч. 15 ст. 8 Закона № 223-Ф3 с 01.01.2020 г. была внесена возможность участия «самозанятых граждан» в закупках для субъектов малого и среднего бизнеса ${ }^{7}$.

Таким образом, участие физического лица в публичных закупках, а также заключение и исполнение соответствующего договора обязывает заказчика, как налогового агента, удержать подоходный налог в размере $13 \%$ для резидентов и $30 \%$ для не-

7 Федеральный закон от 27.12.2019 г. № 474-ФЗ «О внесении изменений в статью 25.1 Федерального закона «О развитии малого и среднего предпринимательства в Российской Федерации» и статью 8 Федерального закона «О закупках товаров, работ, услуг отдельными видами юридических лиц». URL: http://www.kremlin.ru/acts/bank/44979 
резидентов, а также все иные сборы и обязательные платежи в бюджеты бюджетной системы Российской Федерации, если данное условие включено в договор.

\section{НДФЛ в публичных закупках}

Для начала представим расчет получаемой физическим лицом суммы по договору, заключенному по итогам процедуры публичной закупки. Он достаточно прост: в 2021 г. при цене договора в 30000 руб. НДФЛ для физического лица в 13\% составит 3900 руб., а страховые взносы в размеpe $30 \%$ (ПФР - 22\%, ФСС - 2,9\%, ФФОМС$5,1 \%$ - 9000 руб. Следовательно, на руки физическое лицо-контрагент получит 17100 руб. при включении сборов и обязательных платежей в цену договора и 26100 руб., если сборы и обязательные платежи уплачивает заказчик самостоятельно.

Вместе с тем с 1 января 2021 г. вступили в силу изменения, устанавливающие прогрессивную шкалу налогообложения для физических лиц, доход которых превышает 5 млн руб. в год 8 . Норма определяет, что по доходам, превышающим установленную величину, физическое лицо обязано уплатить НДФЛ в размере 15\% (за исключением доходов от продажи любого имущества физических лиц).

Несмотря на относительное спокойствие Минфина России, указывающего, что «Основными направлениями бюджетной, налоговой и таможенно-тарифной политики Российской Федерации на 2020 год и на плановый период 2021 и 2022 годов введение прогрессивной шкалы налогообложения доходов физических лиц также не предусмотрено» ${ }^{9}$, мы прогнозируем возникновение ряда налоговых нарушений, связанных с выполнением заказчиком обязанности налогового агента.

Взимать НДФЛ по повышенной ставке обязаны заказчики, как налоговые аген-

8 Федеральный закон от 23.11.2020 г. № 372-Ф3 «О внесении изменений в часть вторую Налогового кодекса Российской Федерации в части налогообложения доходов физических лиц, превышающих 5 миллионов рублей за налоговый период».URL: http://kremlin.ru/acts/bank/46118

9 Письмо Минфина России от 8 апреля 2020 г. № 2401-08/27934 «O рассмотрении обращения». URL: https:// www.garant.ru/products/ipo/prime/doc/74178534/ ты или налоговые органы, если доход физического лица, превышающий 5 млн руб., был получен у нескольких налоговых агентов. В данной связи возникает ряд рисков для заказчика, о которых должностные лица, отвечающие за осуществление публичных закупок, могут забыть или не знать.

Во-первых, заказчик, заключая договор с физическим лицом на стоимость, превышающую 5 млн руб., обязан в договоре установить условие о применении прогрессивной шкалы подоходного налога, а бухгалтерия - произвести удержания подоходного налога по двум ставкам: до 5 млн руб. 13\%, свыше 5 млн руб. - 15\%.

Во-вторых, заказчик при заключении с одним и тем же физическим лицом нескольких договоров, общая сумма которых превышает 5 млн руб., обладает информацией о сумме выплат данному физическому лицу, следовательно, как налоговый агент, он обязан производить удержание подоходного налога в размере 15\% со всех сумм, превышающих в совокупности 5 млн руб.

Таким образом, необходимо тесное взаимодействие должностных лиц заказчика, отвечающих за реализацию публичных закупок, с работниками бухгалтерии заказчика во всех случаях заключения, исполнения и оплаты по договорам, заключаемым с физическими лицами. Рассмотрение договорных отношений заказчиков с физическими лицами демонстрирует наличие ряда налоговых рисков, которые влекут дополнительные финансовые расходы заказчиков на оплату сборов и иных обязательных платежей за физических лиц.

\section{Налог на профессиональный доход в публичных закупках}

Представленная выше ситуация на фоне недавно введенного и территориально расширенного эксперимента в части вовлечения физических лиц в бизнес-процессы по средствам регистрации как «самозанятых граждан» с применением специального налогового режима - НПД, вызвала заинтересованность многих работодателей в найме физических лиц не по трудовому договору, а как «самозанятых».

Для массового предотвращения подобных случаев установлен запрет нанимать 
организации - бывшему работодателю «самозанятого гражданина», состоявшего с ней ранее в трудовых отношениях, до истечения двух лет со дня увольнения. В противном случае налоговый орган может переквалифицировать договор гражданско-правового характера в трудовой и доначислить недоимку в размере НДФЛ.

Аналогичная ситуация и с заказчиками, которые также попали в группу риска доначисления налоговыми органами НДФЛ в случаях заключения договора с «самозанятым гражданином», ранее являвшимся работником заказчика, если после увольнения не истек двухлетний срок.

Необходимо отметить, что «самозанятый гражданин» не является плательщиком НДФЛ. Он самостоятельно уплачивает НПД по ставке 4\% (с дохода, полученного от физического лица) и по ставке $6 \%$ (с дохода, полученного от юридического лица). Перечень разрешенных видов деятельности для «самозанятых граждан» не ограничен, однако запреты на применение данного специального налогового режима установлены в ч. 2 ст. 4, ч. 2 ст. 6 Закона № 422-ФЗ.

Для заказчика, с одной стороны, выгодно заключать договоры с «самозанятыми гражданами», поскольку последние сами уплачивают налоги с перечисленной суммы. Заказчику необходимо при заключении договора проверить и указать непосредственно в договоре статус «самозанятого гражданина» из соответствующего реестра, включить в обязанность контрагента уплатить все налоги, установить ответственность за нарушение сроков и порядка выдачи соответствующих чеков, а также истребовать реквизиты специального банковского счета для оплаты выполненного обязательства. Например, стоимость договора 30000 руб., следовательно «самозанятый гражданин» получит 30000 руб., уплатив самостоятельно после этого налог в размере 1800 руб. По сравнению с выплатой подоходного налога, сборов и иных обязательных платежей за контрагента - физическое лицо экономия (выгода) финансовых средств заказчика более чем очевидна.

С другой стороны, заключение договоров заказчиками с «самозанятыми гражданами» влечет дополнительные риски, свя- занные с четким пониманием предмета договора, доходы от исполнения которого контрагентом могут рассматриваться как объект налогообложения НПД, а также необходимостью постоянного мониторинга статуса и суммы годового дохода «самозанятого гражданина».

Например, доходы, полученные физическим лицом от аренды заказчиком жилого помещения, будут являться объектом налогообложения НПд, а доходы, полученные физическим лицом от заказчика за аренду нежилого помещения или за приобретение недвижимого имущества, не признаются объектом налогообложения НПД. Следовательно, договоры на аренду нежилого помещения или на приобретение недвижимого имущества не могут быть заключены с «самозанятым гражданином».

Несмотря на то, что ни Законом № 44Ф3, ни Законом № 223-ФЗ ценовых ограничений для заключения договоров с «самозанятыми гражданами» не установлено, заказчикам необходимо знать, что общая сумма дохода «самозанятого гражданина» в год не должна превышать 2,4 млн руб. Превышение указанной суммы автоматически лишает физическое лицо статуса «самозанятый гражданин», а заказчику возвращает функцию налогового агента с последующей обязанностью удержать подоходный налог и уплатить необходимые страховые взносы ${ }^{10}$. При этом перезаключения договора не требуется.

Таким образом, любое физическое лицо может одновременно заключать договоры с заказчиком и как физическое лицо непосредственно, и как «самозанятый гражданин». Поэтому заказчик обязан понимать, что заключение договора на сумму более 2,4 млн руб. с «самозанятым гражданином» представляет значительные финансовые риски.

Указанное находит подтверждение в письме Минфина России, согласно которому наличие ранее заключенных договоров между юридическим и физическим лицами не является ограничением для применения указанным физическим лицом специального налогового режима НПД в от-

10 Письмо Федеральной налоговой службы от 20 февраля 2019 г. № СД-4-3/2899@ «О применении налога на профессиональный доход», п. 10. URL: https:// www.garant.ru/products/ipo/prime/doc/72079182/ 
ношении дохода, полученного от осуществления деятельности в рамках договора, заключенного между физическим лицом, являющимся налогоплательщиком НПД, и указанным юридическим лицом, при соблюдении условий, предусмотренных Законом № 422-Ф3 ${ }^{11}$.

Кроме того, заказчикам, заключившим договор с «самозанятым гражданином», необходимо четко понимать, что доходы, полученные в натуральной форме, не признаются объектом налогообложения и не подпадают под объект налогообложения по НПД (п. 11 ч. 2 ст. 6 Закона № 422-Ф3). Например, оплата заказчиком за контрагента стоимости проезда, проживания и прочих расходов в месте выполнения работ, оказания услуг признается доходом налогоплательщика ${ }^{12}$, следовательно требуется удержание подоходного налога. Более того, контрагент может получить профессиональный налоговый вычет по НДФЛ в сумме произведенных им и документально подтвержденных расходов (п.2 ст. $221 \mathrm{HK}$ РФ) ${ }^{13}$. Аналогичное мнение в отношении налоговых вычетов, установленных ст. 218221 НК РФ, представлено в позиции Департамента налоговой и таможенной политики Минфина России ${ }^{14}$.

В данной связи актуальными и прогнозируемыми представляются вопросы:

о квалификации налоговыми органами договоров, часто заключаемых заказчиком с одним и тем же физическим лицом, использующем НПД. Будут ли налоговые органы пытаться его переквалифицировать в трудовой договор и доначислять НДФЛ, а также страховые взносы?

о штрафных санкциях (за исключением доначисления НДФЛ и страховых взносов) для заказчика в случае потери физическим лицом статуса «самозанятого гражданина» в процессе исполнения договора.

11 Письмо Департамента налоговой политики Минфина России от 20 ноября 2020 г. № 03-11-11/101180 «Об особенностях применения налога на профессиональный доход». URL: https://www.garant.ru/products/ipo/prime/ doc/74946610/

12 Письмо Минфина России от 02.02.2018 г. № 03-04-06/6138. URL: http://www.consultant.ru/

13 Письмо Минфина России от 26.04.2019 г. № 03-04-06/31273. URL: http://www.consultant.ru/

14 Письмо Минфина России от 24.09.2019 г. № 03-11-11/73352. URL: http://www.consultant.ru/

\section{Налогообложение, применяемое ИП в публичных закупках}

Вариант заключения заказчиком договора с ИП представляется оптимальным, поскольку ИП самостоятельно исчисляет и платит налоги.

Для ИП в сфере публичных закупок важен режим налогообложения, который он выбирает самостоятельно. В НК РФ определено два налоговых режима: общий и специальный. По общему режиму налогообложения уплачиваются все налоги в зависимости от наличия объекта налогообложения у ИП, включая НДФЛ. Специальный режим налогообложения позволяет ИП выбрать один из специальных режимов налогообложения, в том числе: упрощенная система налогообложения (УСН), патентная система налогообложения (ПСН), система налогообложения для сельскохозяйственных товаропроизводителей (ЕСХH); налог на профессиональный доход (НПД).

Кроме того, ИП, уплачивающий НДФЛ по ставке 13\%, также, как и обычное физическое лицо, имеет право на вычеты: стандартные, социальные, инвестиционные, имущественные (за исключением вычетов, связанных с продажей недвижимого имущества или транспортных средств, используемых в предпринимательской деятельности).

Риски заказчика минимальны, поэтому ему при заключении договора достаточно проверить действующий статус ИП на официальном сайте ФНС России. В случае, если ИП в процессе выполнения договорных обязательств сменит налоговый режим на НПД, это не повлечет дополнительных расходов заказчика и также расторжения договора ${ }^{15}$.

Однако, если, по данным единого государственного реестра индивидуальных предпринимателей (ЕГРИП), ИП ликвидировано, а в качестве «самозанятого гражданина» не зарегистрировано, действие договора не прекращается, заказчик обязан уплатить НДФЛ и страховые взносы, как за обычное физическое лицо. Схожая по-

15 Письмо Федеральной налоговой службы от 20 февраля 2019 г. № СД-4-3/2899@ «О применении налога на профессиональный доход», п. 3. URL: https:// www.garant.ru/products/ipo/prime/doc/72079182/ 
зиция изложена Минэкономразвития России в 2016 г. ${ }^{16}$.

Таким образом, в статье выявлены проблемы, связанные с исчислением и взиманием подоходного налога заказчиком с физического лица - контрагента по договору в рамках публичных закупок. Акцентировано внимание на необходимости осуществления мониторинга статуса контрагента - «пограничных состояний», переход которых обязывает заказчика, как налогового агента, удерживать подоходный налог, в том числе с учетом прогрессивной шкалы.

На основании изложенного полагаем необходимым в функционал (регламенты, инструкции) должностных лиц заказчика, отвечающих за публичные закупки, внести изменения, обязывающие последних вести учет налоговых режимов контрагентов (ИП, физического лица и физического лица, применяющего НПД) в течение срока выполнения договорного обязательства, а также осуществлять мониторинг статуса контрагента в целях надлежащего выполнения заказчиком обязанности налогового агента и недопущения налоговых правонарушений.

16 Письмо Минэкономразвития России от 13 октября 2016 г. № Д28и-2764 «О необходимости внесения изменений в госконтракт, заключенный с физлицом, получившим в ходе исполнения контракта статус ИП».

\section{СПИСОК ЛИТЕРАТУРЫ (REFERENCES)}

Кикавец В.В., Копина А.А. 2018. О балансе публичных и частных финансовых интересов в контрактной системе сферы закупок при увеличении размера ставки налога на добавленную стоимость. Финансовое право. № 12. C. 17-19. [Kikavets V.V., Kopina A.A. 2018. On the balance between public and private financial interests in the contractual system of procurements in raising the value added tax rate. Finansovoe pravo. No 12. PP. 17-19. (In Russ.)]

Кикавец В.В. 2019а. НДС и УСН в процессе финансирования государственных закупок как дисбаланс публичных и частных финансовых интересов. Налоги. № 6. С. 19-23. [Kikavets V.V. 2019. The value added tax and the simplified taxation system in the state procurement financing process as an imbalance between public and private financial interests. Nalogi. No 6. PP. 19-23. (In Russ.)]

Кикавец В.В. 2019b. Налог на государственные закупки, как основа баланса публичных и частных интересов в процессе финансового обеспечения государственных и муниципальных закупок в условиях развития цифровой экономики. Финансовое право. № 5. C. 38-41. [Kikavets V.V. 2019. The tax on state procurements as a basis of the balance between public and private interests in the process of financial support of state and municipal procurements in the digital economy development conditions. Finansovoe pravo. No 5. PP. 38-41. (In Russ.)] 
In citation: Belorusskiy Ekonomicheskiy zhurnal. 2021. No 2. PP. 118-124.

Belarusian Economic Journal. 2021. No 2. PP. 118-124.

\title{
TOPICAL ISSUES OF INCOME TAXATION IN PUBLIC PROCUREMENT IN THE RUSSIAN FEDERATION
}

\author{
Vitaly Kikavets ${ }^{1}$ \\ Author affiliation: ${ }^{1}$ The Russian State University of Justice (Moscow, Russia). \\ Corresponding author: Vitaly Kikavets (viking0071@mail.ru).
}

ABSTRACT. The article examines the effect of individuals on taxation while taking part in public procurement in the Russian Federation. We analyzed current legislation standards given their enforcement practice for the case. Thus, a range of problems relating to calculating and withholding income tax payments in public procurement are brought out. We studied such issues as: individual's (being a counterparty under a state (municipal) or civil contract) acquisition or loss of a solo proprietor status, an individual's application of a «self-employed citizen» status (administration of a special tax regime - tax on professional income), the use of a progressive tax scale (tax on the rich from 2021). Suggestions for optimizing the interaction of the customer's officials, aimed at preventing tax violations in procurement, are formulated.

KEYWORDS: public procurement, an individual, income tax, self-employed citizen, professional income tax, customer, tax agent.

JEL-code: K34, H24.

DOI: $10.46782 / 1818-4510-2021-2-118-124$

Received 6.05.2021 